\title{
Field Safety Notices Released by Manufacturers in Cases of FAILURE OF Products FOR InfECtION Testing: Analysis of Cases Reported to the BfArM Between 2005 AND 2007
}

\author{
R. Siekmeier, K. Lisson, D. Wetzel \\ Federal Institute for Drugs and Medical Devices, Bonn, Germany
}

\begin{abstract}
The European Directive 98/79/EC for in vitro diagnostic medical devices (IVD) regulates marketing and post marketing surveillance of IVD in the European Economic Area. Manufacturers have to inform the responsible Competent Authorities (CA) about incidents and field safety corrective actions (FSCA) related to IVD. In Germany, the Federal Institute for Drugs and Medical Devices (BfArM) is the responsible CA for most IVD, only few IVD as specified in Annex II of the Directive are under the responsibility of the Paul Ehrlich Institute (PEI). In case of a FSCA manufacturers have to inform customers by means of a Field Safety Notice (FSN) which should be sent to BfArM prior to release and is published on the BfArM homepage. Between beginning of 2005 and end of 2007 the BfArM received a total of 1025 reports regarding IVD. From these, 38 related to tests, reagents, calibrators, and control materials for infection testing, 13 related to analysers and general consumables $(\mathrm{n}=8$ and $\mathrm{n}=5$, respectively) based on culture techniques, and 7 related to analysers and general consumables ( $\mathrm{n}$ $=5$ and $\mathrm{n}=2$, respectively) based on molecular biological methods. FSCA were performed in Germany in $32(84.2 \%)$ of all notifications related to tests reagents, calibrators, and control materials as well as in 13 $(100 \%)$ and $7(100 \%)$ of notifications related to analysers and consumables based on culture techniques and molecular biological methods, respectively. A number of relevant deficiencies regarding the quality of the FSN were separately demonstrated for FSN in German and English language. In brief, manufacturers often sent their FSN to the BfArM with delay. Additionally, a subset of FSN provided insufficient information on the product related risks or the measures to be performed by the customer to mitigate product related risks. Furthermore, customer confirmation forms often were missing in the FSN sent to the BfArM. Our data suggest that for IVD for infection testing FSCA and FSN are frequently performed. For better vigilance performance, manufacturers could shorten the time until release and improve the contents of FSN to ensure the safety of IVD in cases of product related corrective actions.
\end{abstract}

Key words: European Directive 98/79/EC, in vitro diagnostics, infective disease, infection testing, post market surveillance, field safety corrective action, field safety notice

\section{INTRODUCTION}

The European Directive 98/79/EC regulates the conformity assessment, marketing and the post marketing surveillance of in vitro diagnostic medical devices (IVD) within the European Economic Area (EEA) [1]. The regulations of the European Directive have been implemented in Germany by means of the $2^{\text {nd }}$ Amendment to the German Law on Medical Devices (Medizinproduktegesetz, MPG) on January $1^{\text {st }} 2002$ [2]. This has been supplemented by the Ordinance on the Medical Devices Vigilance System (Medizinprodukte-Sicherheitsplanverordnung, MPSV) from June 24th 2002 [3] and the Ordinance on Registration of Medical Devices (DIMDI-Verordnung, DIMDIV) from December $4^{\text {th }} 2002$ [4]. Even though up to now there was no recast of the Directive 98/79/EC the national German regulations were updated recently, incorporating changes as mandated by Directive $2007 / 47 /$ EC [5]. However, our evaluation is based on the national regulations as current during the analysed time period. The regulations, in brief, ensure that manufacturers have to perform a conformity assessment of their IVD and maintain a post market surveillance process for their products including a vigilance reporting system for adverse incidents. For most IVD, except a subset of those listed in Annex II parts A and B of Directive 98/79/EC and tests for professional use, for which a Notified Body has to be involved, manufacturers perform the conformity assessment completely under their own responsibility. The successful completion, including documentation of the conformity assessment, is an obligatory prerequisite for CE labelling, followed by marketing of the product in the European Community (EC) and the EEA. Prior to marketing, manufacturers have to notify the national CA of all countries in which they plan to introduce their product into the market. 
Table 1. Responsibilities of BfArM and PEI regarding IVD [1-3, 7$]$.

\begin{tabular}{|c|c|c|}
\hline Products for immune haematological testing and tissue typing: & Annex of Directive 98/79/EC & Responsibility \\
\hline Blood groups of the $\mathrm{AB} 0$ system 1,2 & $\mathrm{IIa}$ & PEI \\
\hline Blood groups of the Rhesus system $(\mathrm{C}, \mathrm{c}, \mathrm{D}, \mathrm{E}, \mathrm{e})^{1,2}$ & $\mathrm{IIa}$ & PEI \\
\hline Blood groups of the Kell system 1,2 & $\mathrm{IIa}$ & PEI \\
\hline Blood groups of the Duffy and the Kidd system 1,2 & $\mathrm{IIb}$ & PEI \\
\hline Irregular anti-erythrocyte antibodies ${ }^{1,2}$ & IIb & PEI \\
\hline Markers for HLA ${ }^{3}$ typing, markers DR, A and B 1,2 & $\mathrm{IIb}$ & PEI \\
\hline \multicolumn{3}{|l|}{ Products for infection testing: } \\
\hline Markers of HIV 4 infection (HIV-1 and HIV-2) 1,2 & $\mathrm{IIa}$ & PEI \\
\hline HTLV-I ${ }^{5}$ und HTLV-II 1,2 & $\mathrm{IIa}$ & PEI \\
\hline Hepatitis B, C und D 1,2 & $\mathrm{IIa}$ & PEI \\
\hline Congentital infection with rubella 1,2 & IIb & PEI \\
\hline Congenital infection with toxoplasma 1,2 & $\mathrm{IIb}$ & PEI \\
\hline $\mathrm{CMV}^{1,2,6}$ & IIb & PEI \\
\hline Chlamydia 1,2 & IIb & PEI \\
\hline \multicolumn{3}{|l|}{ Other products: } \\
\hline Tumor marker PSA 1,7 & $\mathrm{IIb}$ & BfArM \\
\hline Hereditary diseases phenylketonuria and & & \\
\hline Down syndrome (trisomy 21 , including software) ${ }^{1}$ & $\mathrm{IIb}$ & BfArM \\
\hline \multicolumn{3}{|l|}{ Products for self testing: } \\
\hline Systems for measurement of blood glucose 1 & IIb & BfArM \\
\hline
\end{tabular}

${ }^{1}$ Reagents and reagent products for detection, confirmation and quantification; ${ }^{2}$ Analysers on which these tests are performed are in the responsibility of the BfArM; ${ }^{3} \mathrm{HLA}$ : Human leukocyte antigen; ${ }^{4} \mathrm{HIV}$ : Human immune deficiency virus; ${ }^{5} \mathrm{HTLV}$ : Human T-cell leukaemia virus; ${ }^{6} \mathrm{CMV}$ : Cytomegalovirus; ${ }^{7} \mathrm{PSA}$ : Prostate specific antigen.

After the initial marketing of a product, manufacturers are obliged to systematically review the performance of their devices in the market, to report incidents and to implement field safety corrective actions (FSCA), including recalls as necessary. These are to be reported to the responsible CA for vigilance. In Germany the Federal Institute for Drugs and Medical Devices (BfArM, Bundesinstitut für Arzneimittel und Medizinprodukte) and the Paul Ehrlich Institute (PEI) are responsible for collection and evaluation of incident reports related to IVD. The PEI is responsible for a subset of IVD for infection testing and immune haematological testing as well as tissue-typing listed in Annex II of Directive 98/79/EC [1, 3, 6]. Although, even for reagents and tests under the responsibility of the PEI, the laboratory analysing equipment on which these tests are run are within the responsibility of the BfArM (see Table 1). Consequently, both CA work closely together in risk evaluation of products for immune haematological testing and infection testing to ensure product safety of IVD and blood products.

According to the MPSV, professional operators and users of IVD have to report incidents to the CA which they observe during application of the products $[3,7-9]$. The same obligation applies to pharmacies and other retail traders if incidents related to over the counter-products (OTC-products) sold by them come to their attention. When performing the assessment, it is the task of the CA to characterise the risk (in terms of probability of occurrence of harm and severity of the harm) and to assess it for acceptability. This process is initiated after risk assessment and mitigation by the responsible manufacturer. In case of unacceptable risk levels, the necessary corrective action needs to be determined and executed. If manufacturers have already taken the measures under their own responsibility, the CA decides whether these are adequate for risk mitigation. Any necessary field safety corrective action (FSCA) performed by the manufacturers must be effectively communicated to all customers and users in the market. This is typically done by field safety notices (FSN), which need to be communicated to the vigilance CA for the information and publication via the internet. The requirements for FSN are described in the Guidelines on a Medical Devices Vigilance System [8]. In brief, FSN from manufacturers clearly need to address the underlying problem and describe measures to minimise the product related risk. Further, the FSN should include the communication information for contact in case of questions and a form sheet to be sent back to the manufacturer to confirm the receipt of the FSN by the customer may be included. Manufacturers are not allowed to include any type of advertising for their products in a FSN. 
As CE-marked devices can be moved and marketed freely in the entire EC and EEA, there is a need for an effective information exchange between national CA, in particular when FSCA are initiated. The IVD-Directive therefore requires that European CA exchange with each other and the European Commission information on issues that led to corrective actions. Having been informed by a National Competence Authority Report, all CA can monitor the corrective action in their area of responsibility and evaluate whether similar products of other manufacturers may also be affected by the observed problem.

Up to now, only a few data have been published analysing the number of cases reported to BfArM or PEI and evaluating the results of the market surveillance system. These publications provide data regarding the sources of notification as well as underlying product failure modes and the resulting corrective actions for specific IVD [10-17]. However, there are no published data analysing the quality of FSN in cases of FSCA. The aim of our study was, therefore, to analyse in detail FSN for products for infection testing in regard to their time of publication and the quality of their information. This product group is of special interest, because of their wide distribution and role in public health maintenance.

\section{Methods}

All notifications on IVD received by the BfArM between the beginning of 2005 (the beginning of publication of FSN on the homepage of the BfArM) and the end of 2007 were included. Detailed analysis was made for tests and reagents for infection testing (including special culture media (e.g., for susceptibility testing), calibrators, and control materials) except those lying in the responsibility of the PEI as well as analysers and their general consumables (e.g., buffers and general culture media) based on culture methods or molecular biological methods. In cases of analysers and consumables based on molecular biological methods only those cases affecting the safety of infection testing or laboratory personnel were included whereas a few subsets of cases for other testing were excluded. A large number of cases related to analysers based on immunological methods were excluded because these analysers are frequently multifunctional analysers serving predominantly for diagnostics in clinical chemistry (enzymes, substrates, electrolytes, proteins, hormones and therapeutic drug monitoring). Analyses of the included cases were made in specific subgroups of the products regarding the types of the product (analysers $v s$. consumables) and the underlying analytical principles (products based on cultural, immunological and molecular biological methods) in order to provide more detailed data regarding the product failures, the corresponding corrective measures and the FSN.

\section{RESULTS}

\section{Number AND SOURCES OF REPORTS}

Within the observation period, BfArM received a total of 1025 reports. The annual number of reports increased from 207 in 2005 to 583 in 2007 . The vast majority of reports were received from manufacturers. In contrast, the number of reports from other sources, e.g., other CA and users were negligible. However, there were no relevant differences between the product groups with regard to the source of notification to the BfArM.

\section{Product Groups}

From a total of 1025 notifications, $58(5.7 \%)$ affected products for infection testing included into our study. From the latter, 38 notifications were related to tests, reagents, calibrators, and control materials (predominantly IVD based on cultural or immunological methods), whereas 20 were related to the included analysers or general consumables. Analysers were more frequently subject of notification than their consumables (13 vs. 7, respectively). In addition, there were more reports on analysers and consumables based on cultural methods than for those based on molecular biological techniques (see Table 2).

\section{Product Failures And Corrective ACtions in Tests, Reagents, Calibrators and Control MATERIALS}

In the group of tests, reagents, calibrators, and control materials the underlying root causes of product failures were identified in 34 cases $(89.5 \%)$. In the remaining cases, the root causes were not identified ( $\mathrm{n}=$ $2,5.3 \%$ ) or a product failure was definitively excluded by the investigations of the manufacturers ( $n=2$, $5.3 \%$ ). None of the reported cases were caused by a user error. Most frequently, the underlying root causes of product failure were manufacturing errors, material defects, miss of specification, labelling error, and microbial contamination, whereas other causes played

Table 2. Analysers and their general consumables included into the study $(\mathrm{n}=20)$.

\begin{tabular}{l|c|c|c}
\hline & $\begin{array}{c}\text { Product based on cultural or } \\
\text { biochemical methods or staining }\end{array}$ & $\begin{array}{l}\text { Product based onmolecular } \\
\text { biological methods }{ }^{2}\end{array}$ & Total no. of products \\
\hline Analyser & 8 & 5 & 13 \\
Consumable & 5 & 2 & 7 \\
Total no. of products & 13 & 7 & 20 \\
\hline
\end{tabular}

${ }^{1}$ e.g., culture, strain differentiation, susceptibility testing, or staining; ${ }^{2}$ e.g., polymerase chain reaction (PCR), or hybridisation assays. 
Table 3. Product failures of tests, reagents, controls, calibrators and culture media for infection testing $(\mathrm{n}=38)$.

\begin{tabular}{lcc}
\hline Product failure & $\begin{array}{c}\text { All } \\
\mathrm{n}(\%)\end{array}$ & $\begin{array}{c}\text { Subset with FSCA } \\
\mathrm{n}(\%)\end{array}$ \\
\hline Number of cases & $38(100)$ & $32(100)$ \\
No product failure & $2(5.3)$ & $0(0)$ \\
User error & $0(0)$ & $0(0)$ \\
Root cause not identified & $2(5.3)$ & $2(6.3)$ \\
Product failure identified & $34(89.5)$ & $30(93.7)$ \\
Material defect & 6 & 5 \\
Software error & 1 & 1 \\
Calibration error & 2 & 2 \\
Electrical error & 0 & 0 \\
Mechanical error & 0 & 0 \\
Miss of specification & 6 & 5 \\
Manufacturing error & 8 & 7 \\
Incorrect instructions for use & 2 & 2 \\
Non-microbial contamination & 0 & 0 \\
Packaging error & 1 & 1 \\
Microbial contamination & 3 & 3 \\
Interference by other substances & 1 & 0 \\
Constructional fault & 0 & 0 \\
Labelling error & 4 & 4 \\
\hline
\end{tabular}

only minor roles (see Table 3 ). In 32 cases (30 cases with identified root causes and 2 cases in which the underlying root cause remained unclear) field safety corrective actions (FSCA) were performed by the manufacturers (see Table 3).

Corresponding corrective actions were performed in 33 cases $(86.8 \%)$ and were predominantly customer information, recall (in case of a recall a customer information is mandatory) and modification of production and/or quality management whereas other corrective actions were much less frequent. A subset of cases with consecutive FSCA $(\mathrm{n}=32)$, which served as a basis for the FSN analysed in this study, was not different (see Table 4).
Table 4. Corrective actions for tests, reagents, controls, calibrators, and culture media for infection testing $(\mathrm{n}=38)$.

\begin{tabular}{lcc}
\hline Type of corrective action & $\begin{array}{c}\text { All } \\
\mathrm{n}(\%)\end{array}$ & $\begin{array}{c}\text { Subset with FSCA } \\
\mathrm{n}(\%)\end{array}$ \\
\hline Number of cases & $38(100)$ & $32(100)$ \\
No corrective actions & $5(13.2)$ & $0(16.7)$ \\
Corrective actions $^{1}$ & $33(86.8)$ & $32(83.3)$ \\
$\quad$ Product recall/batch recall & 23 & 23 \\
Cessation of marketing & 2 & 2 \\
Change of design & 7 & 6 \\
Modification of production & & \\
and/or quality management & 22 & 22 \\
Customer information & \\
Modification of & 32 & 32 \\
the instruction for use & 5 & 4 \\
Software-update & 4 & 4 \\
Modification of labelling & 2 & 2 \\
Modification of raw material & 4 & 3 \\
Customer education & & 0 \\
\hline
\end{tabular}

${ }^{1}$ Multiple entries for the different subgroups of corrective actions were allowed; ${ }^{2}$ Alone or in combination with a recall (in case of a recall customer information is mandatory); ${ }^{3} \mathrm{Educa}-$ tion of a single customer, e.g., after a user error was not defined to be a customer education.

\section{Field Safety Notices in Cases of Field Safety Corrective Actions in Tests, Reagents, Calibrators, and Control Materials}

Field safety notices (FSN) were analysed with regard to the time delay between the notification of the BfArM by the manufacturer and the receipt of the FSN by the BfArM and the quality of FSN. The latter included the description of the product failure, the description of the required measures in order to minimise the risk and the existence of a customer confirmation sheet to confirm the receipt of the FSN to the manufacturer. Analyses were made separately for FSN in German and English language (Fig. 1A and B, re-

Table 5. Quality of FSN in cases of FSCA related to tests, reagents, controls, calibrators, and culture media for infection testing $(\mathrm{n}=32)$.

\begin{tabular}{|c|c|c|c|c|}
\hline & $\begin{array}{c}\text { Received } \\
\mathrm{n}\end{array}$ & $\begin{array}{c}\text { Missing } \\
\mathrm{n}\end{array}$ & $\begin{array}{c}\text { Sufficient } \\
\mathrm{n}\end{array}$ & $\begin{array}{c}\text { Insufficient } \\
\mathrm{n}\end{array}$ \\
\hline \multicolumn{5}{|l|}{ German version of the FSN } \\
\hline Description of the product failure & 31 & $1^{1}$ & 29 & 2 \\
\hline Description of the required measures & 31 & 11 & 29 & 2 \\
\hline Confirmation form part of customer information & 24 & $8^{1}$ & 24 & 0 \\
\hline \multicolumn{5}{|l|}{ English version of the FSN } \\
\hline Description of the product failure & 26 & $6^{1}$ & 25 & 1 \\
\hline Description of the required measures & 26 & $6^{1}$ & 25 & 1 \\
\hline Confirmation form part of customer information & 18 & $14^{1}$ & 18 & 0 \\
\hline
\end{tabular}

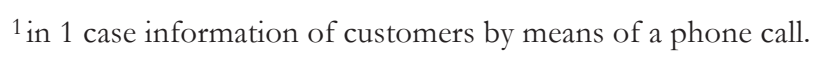


spectively). German and English FSN were received in $31(96.9 \%$; in the remaining case the few German customers were informed via a phone call) and 26 cases (in one more case the few customers were informed via a phone call) of the analysed FSCA. In about the half of all notifications, there was no time delay between the notification of the BfArM by the manufacturer and the receipt of the FSN by the BfArM, i.e., the FSN was sent to the BfArM together with the notification. However, in the remaining cases, there was a strong delay between the receipt of the notification and the FSN (see Fig. 1). In the vast majority of the received German FSN ( $\mathrm{n}=29)$, the product failure and the required measures to be performed by the customer were sufficient. However, only in 24 cases a customer confirmation form was part of the FSN (see Table 5). Even in 25 of the received English FSN, there was a sufficient description of product failure and the required measures to be performed by the customer. However, customer confirmation forms were part of the FSN in 18 cases only (see Table 5).

\section{Product Failures and Corrective ACtions Analysers and General Consumables}

No relevant differences were observed between analysers based on cultural and molecular biological methods, and their corresponding general consumables, respectively. Therefore, in our further analyses we did not differentiate with regard to the underlying analytical principle. Analysers were more frequently subject of a notification to the BfArM than their general consumables. In the 13 notifications related to analysers, a software error has been identified to be the cause in 12 cases $(92.3 \%)$; the remaining case $(7.7 \%)$ was due to a user error (see Table 6). A different behaviour was observed in consumables, where 6 cases were caused by a product failure and one further case by a user error. However, in this group there was a very different pattern of underlying root causes of the reported product failures (see Table 6).

Corresponding FSCA were performed in all cases $(n=20)$. There were no differences regarding the
Table 6. Product failures of analysers and general consumables for infection testing $(\mathrm{n}=20)$.

\begin{tabular}{|c|c|c|}
\hline Product failure & $\begin{array}{l}\text { All analysers }{ }^{1} \\
\text { n }(\%)\end{array}$ & $\begin{array}{c}\text { All general } \\
\text { consumables } 1 \\
\text { n }(\%)\end{array}$ \\
\hline Number of cases & $13(100)$ & $7(100)$ \\
\hline No product failure & $0(0)$ & $0(0.0)$ \\
\hline User error & $1(7.7)$ & $1(14.3)$ \\
\hline Root cause not identified & $0(0)$ & $0(0)$ \\
\hline Product failure identified & $12(92.3)$ & $6(85.7)$ \\
\hline Material defect & 0 & 1 \\
\hline Software error & 11 & 1 \\
\hline Calibration error & 0 & 0 \\
\hline Electrical error & 0 & 0 \\
\hline Mechanical error & 0 & 0 \\
\hline Miss of specification & 0 & 1 \\
\hline Manufacturing error & 0 & 1 \\
\hline Incorrect instructions for use & 0 & 0 \\
\hline Non-microbial contamination & 0 & 0 \\
\hline Packaging error & 0 & 0 \\
\hline Microbial contamination & 0 & 1 \\
\hline Interference by other substances & 0 & 0 \\
\hline Constructional fault & 1 & 0 \\
\hline Labelling error & 0 & 1 \\
\hline
\end{tabular}

${ }^{1}$ FSCA were performed in all cases.

type of the FSCA between analysers based on culture methods, on the one hand, and those based on molecular biological methods, on the other hand, and their general consumables, respectively. Therefore, no differentiation regarding the underlying analytical technology was made in our analysis. However, there were strong differences regarding the types of the performed FSCA in analysers and general consumables. In detail, the vast majority were customer information (mandatory in cases of recall), softwareupdate, and recall (of the affected software) in analy-
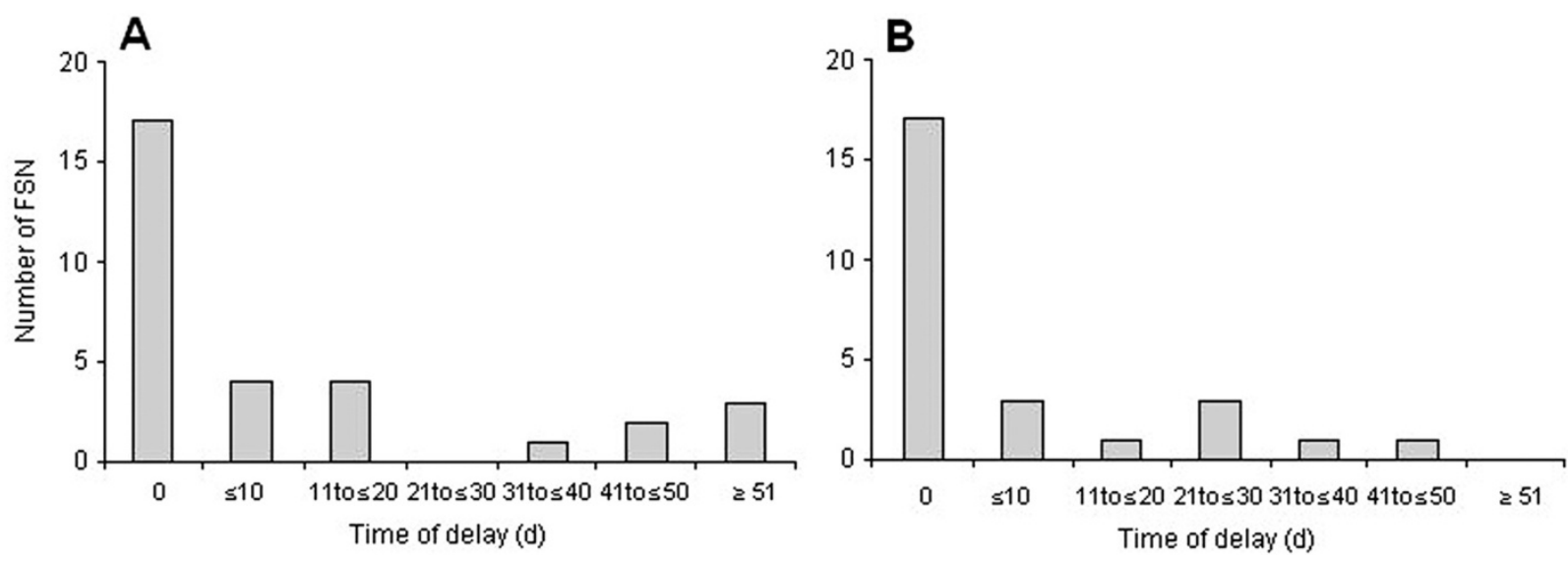

Fig. 1. Time delay in days (d) between notification of the BfArM by the manufacturers and receipt of the FSN in cases with FSCA related to tests, reagents, controls, calibrators and culture media $(\mathrm{n}=32)$; Panel A - FSN in German language ( $\mathrm{n}=31$ received), Panel B - FSN in English language ( $\mathrm{n}=26$ received). 
sers, whereas other measures were of very low frequency (see Table 7). In contrast, in the group of general consumables beside customer information and recall a broader spectrum of corrective measures depending on the identified root causes was observed (see Table 7).

\section{Field Safety Notices in Cases of Field Safety Corrective Actions in Tests, Reagents, Calibrators, AND Control Materials}

FSN were analysed as described above. Some differences were observed with respect to the time delay within the different groups. In the group of culture based analysers and consumables, German FSN were received in all cases $(n=13)$ without any delay and without any differences between analysers and their consumables. English FSN were also received in all cases ( $n=13$ ). However, only about $50 \%$ of the FSN were received without a delay and the delays were longer in the subgroup of consumables (delays between 7 and 98 days in 4 of the 5 cases) than in the subgroup of analysers (delays up to 16 days in 2 of the 8 cases) (see Fig. 2A and B). A different behaviour was observed in molecular biological analysers and their general consumables. In this group German and English FSN were received in 7 and 6 cases (one missing FSN in the subgroup of consumables), respectively. However, German FSN were more frequently received with a delay (delays between 9 and 72 days in 5 of the 7 cases, two cases without a delay in the subgroup of analysers) than English FSN (no delay in 5 of the 6 cases, one delay in the subgroup of analysers) (see Fig. $3 \mathrm{~A}$ and $\mathrm{B})$.

The quality of FSN was analysed in the same groups and subgroups of analysers and their general consumables. For culture based analysers and their consumables, German FSN sufficiently described product failures and required measures in all cases (n $=13$ ) and the customer information form was part of the FSN in 11 cases. Corresponding English FSN also described product problems and required measures sufficiently in all cases $(n=13)$. However, the cus-
Table 7. Corrective actions for analysers and general consumables for infection testing $(\mathrm{n}=20)$.

\begin{tabular}{lcc}
\hline Type of corrective action & All analysers & $\begin{array}{c}\text { All general } \\
\text { consumables } \\
\mathrm{n}(\%)\end{array}$ \\
\hline Number of cases & $13(100)$ & $7(100)$ \\
No corrective actions & $0(0)$ & $0(0)$ \\
Corrective actions ${ }^{1}$ & $13(100)$ & $7(100)$ \\
Product recall/batch recall & 10 & 6 \\
Cessation of marketing & 0 & 1 \\
Change of design & 1 & 0 \\
Modification of production & 1 & 4 \\
and/or quality management & 13 & 7 \\
Customer information & \\
Modification of the & 1 & 3 \\
instruction for use & 11 & 1 \\
Software-update & 0 & 0 \\
Modification of labelling & 0 & 1 \\
Modification of raw material & 1 & 0 \\
Customer education & 3 &
\end{tabular}

${ }^{1}$ Multiple entries for the different subgroups of corrective actions were allowed; ${ }^{2}$ Alone or in combination with a recall (in case of a recall customer information is mandatory); ${ }^{3}$ Education of a single customer, e.g., after a user error was not defined to be a customer education.

tomer confirmation form was part of the FSN in 9 cases only (see Table 8). In the group of molecular biological analysers and their consumables, German FSN were received in all cases $(n=7)$ and provided sufficient information regarding the product failure and the measurers to be performed in 6 cases. The customer conformation sheet was missing in 2 of the FSN in German language. English FSN were received in 6 cases providing sufficient information in 5 cases. However, only in 2 of the English FSN a customer confirmation sheet was included (see Table 8).
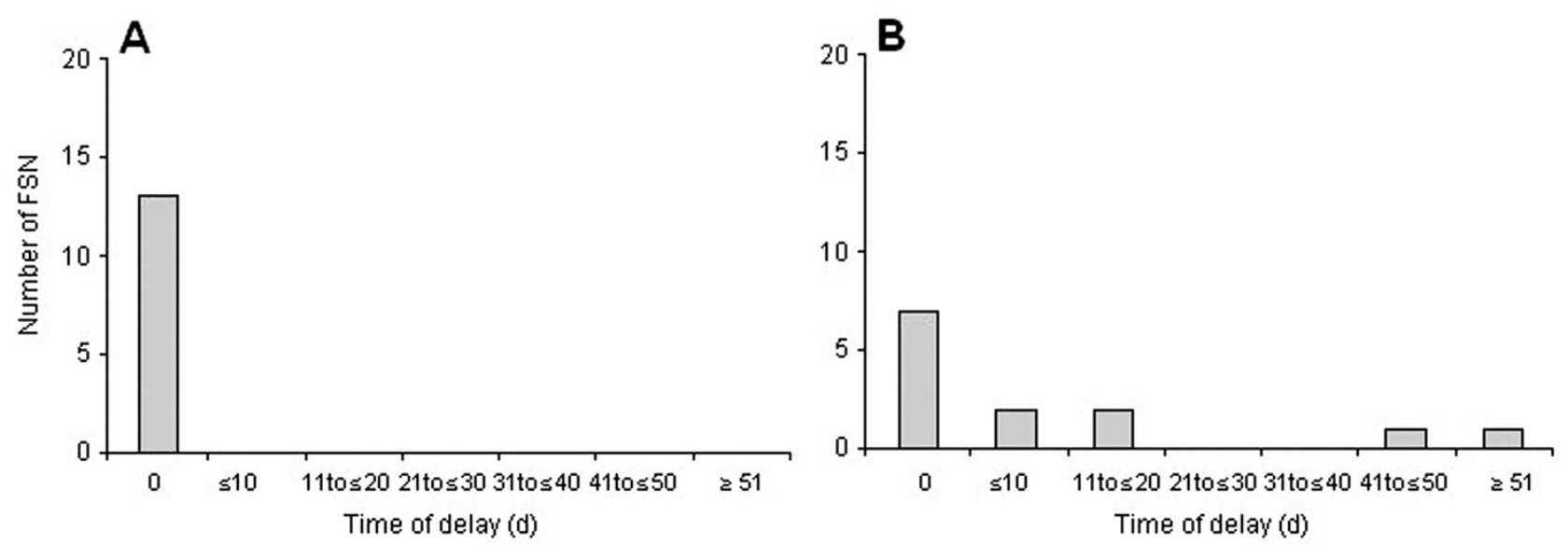

Fig. 2. Time delay in days (d) between notification of the BfArM by the manufacturers and receipt of the FSN in cases with FSCA related to culture based analysers and their general consumables $(\mathrm{n}=13)$. Panel A - FSN in German language $(\mathrm{n}=13$ received), Panel B - FSN in English language ( $\mathrm{n}=13$ received). 

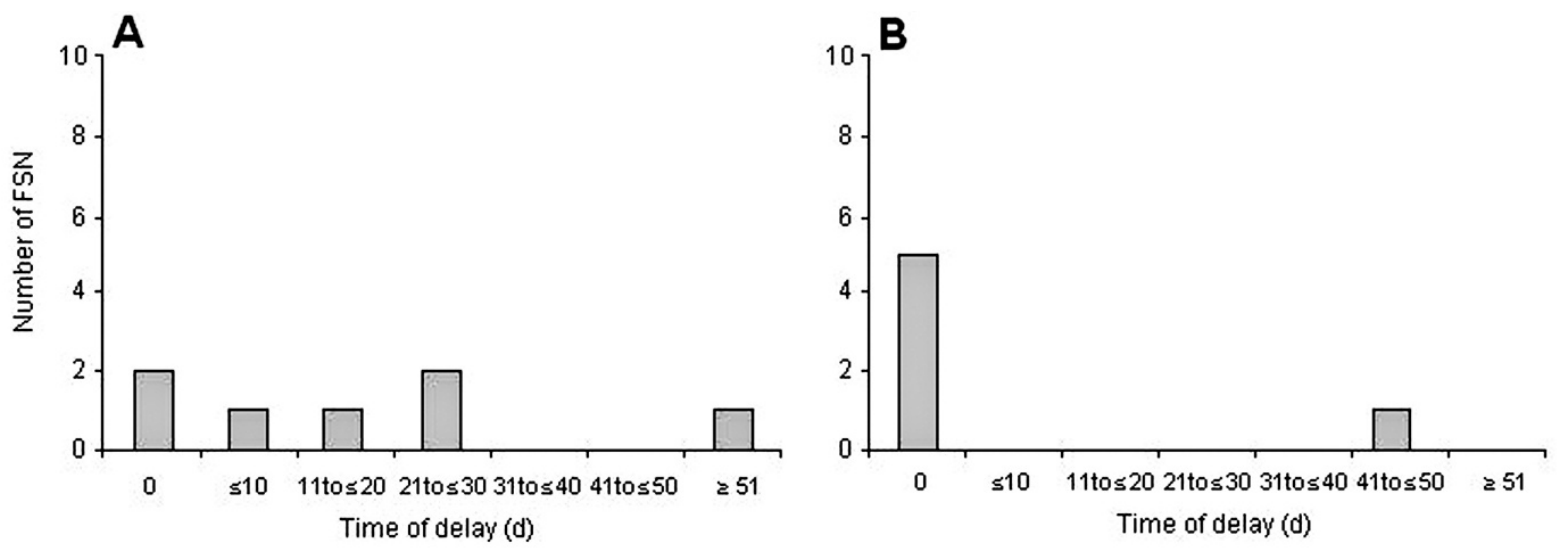

Fig. 3. Time delay in days (d) between notification of the BfArM by the manufacturers and receipt of the FSN in cases with FSCA related to molecular biological analysers and their general consumables $(\mathrm{n}=7)$. Panel A - FSN in German language $(\mathrm{n}=$ 7), Panel B - FSN in English language ( $\mathrm{n}=6$ received).

Table 8. Quality of FSN in cases of FSCA related to analysers and general consumables for infection testing $(\mathrm{n}=32)$.

\begin{tabular}{|c|c|c|c|c|}
\hline & $\begin{array}{c}\text { Received } \\
\mathrm{n}\end{array}$ & $\begin{array}{c}\text { Missing } \\
\mathrm{n}\end{array}$ & $\begin{array}{c}\text { Sufficient } \\
\mathrm{n}\end{array}$ & $\begin{array}{c}\text { Insufficient } \\
\mathrm{n}\end{array}$ \\
\hline \multicolumn{5}{|l|}{$\begin{array}{l}\text { Culture based analysers and general } \\
\text { consumables - German version of the FSN }\end{array}$} \\
\hline Description of the product failure & 13 & 0 & 13 & 0 \\
\hline Description of the required measures & 13 & 0 & 13 & 0 \\
\hline Confirmation form part of customer information & 11 & 2 & 11 & 0 \\
\hline \multicolumn{5}{|l|}{$\begin{array}{l}\text { Culture based analysers and general } \\
\text { consumables - English version of the FSN }\end{array}$} \\
\hline Description of the product failure & 13 & 0 & 13 & 0 \\
\hline Description of the required measures & 13 & 0 & 13 & 0 \\
\hline Confirmation form part of customer information & 9 & 4 & 9 & 0 \\
\hline \multicolumn{5}{|l|}{$\begin{array}{l}\text { Molecular biological analysers and general } \\
\text { consumables - German version of the FSN }\end{array}$} \\
\hline Description of the product failure & 7 & 0 & 6 & 1 \\
\hline Description of the required measures & 7 & 0 & 6 & 1 \\
\hline Confirmation form part of customer information & 5 & 2 & 5 & 0 \\
\hline \multicolumn{5}{|l|}{$\begin{array}{l}\text { Molecular biological analysers and general } \\
\text { consumables - English version of the FSN }\end{array}$} \\
\hline Description of the product failure & 6 & 1 & 5 & 1 \\
\hline Description of the required measures & 6 & 1 & 5 & 1 \\
\hline Confirmation form part of customer information & 2 & 5 & 2 & 0 \\
\hline
\end{tabular}

\section{DisCUSSION}

Until end of 2007, a total number of 1471 cases related to IVD were reported to the BfArM from which 1025 were received since beginning of 2005 . There is an unknown rate of underreporting (from manufacturers and their distributors and especially from users of the affected products) which even cannot be assessed by estimation. Prior analyses of our group have shown that about $5.0 \%$ of notifications were related to laboratory analysers and their general consumables for testing of infectious diseases (including analysers based on immunological methods) [6]. In addition, about $10 \%$ of notifications were related to reagents for testing of infective diseases which are in the responsibility of the BfArM [15]. This demonstrates that products for infection testing are an important group within the group of all IVD. The relevance of these IVD is further increased as these products play a significant role in 
public health due to the epidemiologic character of infective diseases.

In our prior publications we have made detailed analyses of the sources of notification to the BfArM, the underlying product failures, and the consecutive corrective measures performed by the manufacturers $[6,15]$. Only a minority of corrective actions was made internally by the manufacturers without directly affecting the customers. These measures typically improved the safety of future products or product batches which were not in the market at this time. In contrast, most of the corrective actions were field safety corrective actions (FSCA) affecting products already in the market. In these cases, manufacturers are obliged to inform customers by means of a field safety note (FSN) in order to minimise product related risks. In cases of product recalls FSN are mandatory. The requirements of FSN are described in the Guidelines on a Medical Devices Vigilance System [8]. To ensure a rapid minimisation of product related risks these shall be rapidly sent to the customers. However, prior to their distribution in the market FSN should be sent to the responsible CA to ensure that it fulfils the requirements regarding their quality (sufficient description of the product problem and the measures to be performed by the customer (e.g., to discard the product, to enforce additional control mechanisms, to retest patient samples), contact data (e.g., product hotline), and provision of a customer confirmation form. Because of the important role of the FSN in cases of product failure, we now have analysed all FSN in FSCA related to IVD for infection testing from beginning 2005 until end of 2007 . We have chosen to start with the beginning of 2005 as since the mid-2004 FSN are requested by the BfArM for publication on the homepage of the BfArM.

The notifications included in our recent study are a subset of the notifications analysed in our studies before. Therefore, there are no relevant differences regarding the sources of notification, the underlying product problems, and the consecutive corrective measures performed by the manufacturers $[6,15]$. As expected FSCA were performed in the vast majority of cases. However, in the group of tests, reagents, controls, calibrators, and culture media FSCA were performed in only 32 of the 38 cases $(84.2 \%)$, whereas FSCA were performed in all of the cases related to analysers and their general consumables $(n=20)$. Likely, this was due to the more specific and broader risk pattern in the latter product group.

FSN were received in a higher number in the German than English language. This can be explained by the legal requirements according to the MPSV in Germany [3]. In brief, manufacturers are obliged to provide a German FSN for their products marketed in Germany, whereas providing an English FSN for publication on the BfArM homepage is voluntary. Only in about half of the notifications followed by FSCA, FSN were received without a delay, i.e., together with the notification to the BfArM. In several cases, German and English FSN were dated before the notification to the BfArM, even though there was a delay and there were different dates of German and English versions of the FSN. In the group of tests, reagents cali- brators and control materials for infection testing, there were obvious differences between the German and English FSN regarding the time of their receipt by the BfArM. In the group of analysers and their general consumables, we observed differences between the subgroups of IVD based on culture techniques and molecular biological methods. In detail, German FSN in cases of culture based analysers were received without a delay, whereas relevant delays were observed for the corresponding English FSN. In contrast, in cases of FSCA for molecular biological analysers and their general consumables, most English FSN were received by the BfArM without a delay, whereas relevant delays were observed for German FSN. Due to a small number of cases in both subgroups, it cannot be clarified if this observation reflects product specific characteristics or if it is a chance finding caused by an uneven distribution of international manufacturers within these subgroups. However, analysis of the delay times for German and English FSN clearly demonstrates the necessity for their further optimisation with respect to the time of their provision to the BfArM.

In our study we also analysed the quality of information of German and English FSN. In all groups and subgroups included in our study the vast majority of FSN sufficiently described the product related risk and the measures to be performed by the customer in order to minimise the risks. No relevant difference was observed regarding the quality of the information between German and English FSN. However, in a small subset there were differences between the German and English FSN, which were caused by addressing specific local differences of customer qualification and product use. This demonstrates that for a few cases it is necessary to consider these specific aspects in FSN. Advertising played no role in all FSN analysed in our study. Likely, this is due to the professional use character of all IVD for infection testing included in our study and products for lay use might be more prone to advertising by manufacturers. Customer confirmation forms were frequently not included in all groups and subgroups of German and English FSN. In our view customer confirmation forms may be a useful part of FSN in order to facilitate documentation. Therefore, manufacturers should include customer confirmation forms in their FSN.

In our study investigating FSN we have focussed on a specific aspect of the European surveillance system for IVD. Prior publications have shown that the system is functioning, even though it should be further improved in some points (e.g., underreporting of incidents especially from users and reduction of the time delay prior to the reporting of incidents to the responsible CA by the manufacturer). In cases of FSCA customer information is essential for minimisation of product related risk. FSN play a crucial role as they describe the product failure and the measures to be performed for risk reduction. Therefore, FSN should be provided more rapidly to the CA and the affected customers.

Conflicts of interest: The authors declare no conflicts of interest in relation to this article. 


\section{REFERENCES}

1. Directive $98 / 79 / \mathrm{EC}$ of the European Parliament and of the Council of 27 October 1998 on In Vitro Diagnostic Medical Devices (Official Journal L 331, pp. 1-37/Internet: http://europa.eu.int/eur-lex/en/index.html).

2. Medizinproduktegesetz (MPG) in der Fassung der Bekanntmachung vom 7. August 2002 (BGBl. I S. 3147) zuletzt geändert durch Artikel 1 des Gesetzes zur Änderung medizin-produkterechtlicher und anderer Vorschriften vom 14 Juni 2007 (BGBL I S. 1066)/Internet:

www.bfarm.de/de/Medizinprodukte/mp_recht/index.php.

3. Medizinprodukte-Sicherheitsplanverordnung (MPSV) vom 24. Juni 2002 (BGBl. I S. 2131) zuletzt geändert durch Artikel 1 des Gesetzes zur Änderung medizinprodukte-rechtlicher und anderer Vorschriften vom 14. Juni 2007 (BGBL I S. 1068)/Internet:

www.bfarm.de/de/Medizinprodukte/ mp_recht/index.php.

4. Verordnung über das datenbankgestützte Informationssystem über Medizinprodukte des Deutschen Instituts für Medizinische Dokumentation und Information (DIMDI-Verordnung - DIMDIV vom 4. Dezember 2002 (BGBl. I S. 4456) zuletzt geändert durch Artikel 1 des Gesetzes zur Änderung medizinprodukte-rechtlicher und anderer Vorschriften vom 14. Juni 2007 (BGBL I S. 1066) / Internet: www.bfarm.de/de/Medizinprodukte/mp_recht/index.php.

5. Directive 2007/47/EC of the European Parliament and of the Council of 5 September 2007 amending Council Directive 90/385/EEC on the approximation of the laws of the Member States relating to active implantable medical devices, Council Directive 93/42/EEC concerning medical devices and Directive 98/8/EC concerning the placing of biocidal products on the market. Internet: http://eur-lex.europa.eu/ LexUriServ/LexUriServ.do?uri $=$ OJ:L:2007:247:0021:0055:en:PDF.

6. Siekmeier R, Halbauer J, Mientus W, Wetzel D. Safety of laboratory analyzers for infection testing - results of the market surveillance by the BfArM until end 2007. Eur J Med Res 2009; 14 Suppl 4: 216-26.

7. Die Anforderungen der Medizinprodukte-Sicherheitsplanverordnung für in-vitro-Diagnostika im Rahmen des Medizinproduktegesetzes. MedizinProdukteRecht 4, 2002: 120-33.

8. Guidelines on a Medical Devices Vigilance System (MEDDEV 2.12-1 rev. 5/Internet: http://europa.eu.int/comm/enterprise/medical_de vices/guidelinesmed/baseguidelines.htm.
9. Medical Devices Post Market Surveillance: National Competent Authority Report Exchange Criteria and Report Form (GHTF/SG2/N79R8:2006). Internet: www.ghtf.org.

10. Siekmeier R, Lütz J. Experience with post-market surveillance of in-vitro diagnostic medical devices for lay use in Germany. Clin Chem Lab Med 2007; 45: 396-401.

11. Siekmeier R, Will HG. German experience with the European Vigilance System for in vitro diagnostic medical devices 1999-2002. Clin Chem Lab Med 2003; 41: A87 (Abstract).

12. Siekmeier R, Will HG. Safety of lay use products - German experience with the European vigilance system for in vitro diagnostic medical devices. Clin Chem Lab Med 2004; 42: A151 (Abstract).

13. Siekmeier R, Lütz J. Safety of in-vitro-diagnostics for hematology and coagulation testing - Analysis of the reports to the German Competent Authority (BfArM). Transfus Med Hemother 2007; 34: 353-61.

14. Spitzenberger F, Edelhäuser R, Funk M, Halbauer J. Vigilance experience for high-risk IVDs in Europe. Regulatory Affairs J Devices 2007; 15: 157-64.

15. Siekmeier R, Halbauer J, Mientus W, Wetzel D. Safety of reagents for infection testing: Results of the market surveillance by the Federal Institute for Drugs and Medicinal Devices until end 2006. J Physiol Pharmacol 2008; 59 Suppl 6: 629-43.

16. Siekmeier R, Lütz J, Wetzel D. Wie sicher sind Testsysteme zur Diagnostik von Infektionskrankheiten? Bundesgesundheitsblatt Gesundheitsforschung Gesundheitsschutz 2008; 51: 221-34.

17. Halbauer J, Siekmeier R, Funk M. Die Sicherheit von Hochsicherheits-In-vitro-Diagnostika. Internationale und nationale Maßnahmen. Bundesgesundheitsblatt Gesundheitsforschung Gesundheitsschutz 2009; 52: 610-8.

Address for correspondence:

R. Siekmeier

Federal Institute for Drugs and Medical Devices

Kurt-Georg-Kiesinger-Allee 3

53175 Bonn

Germany

E-mail: r.siekmeier@bfarm.de 